\title{
'If You Care About Me, You'll Send Me a Pic' - Examining the Role of Peer Pressure in Adolescent Sexting
}

\author{
Heidi Hartikainen \\ University of Oulu, Finland
}

\author{
Afsaneh Razi \\ University of Central Florida, USA
}

\author{
Pamela Wisniewski \\ University of Central Florida, USA
}

\begin{abstract}
Trigger Warning: This paper contains sensitive topics such as sexual and self-harm and may be triggering.

\section{CCS CONCEPTS}

- Human-centered Computing; • Human computer interaction (HCI); • Empirical studies in HCI;

\section{KEYWORDS}

Online Safety, Social support, Adolescence, Teens, Sexting, Digital Trace Data, Qualitative Analysis, Peer pressure

\section{ACM Reference Format:}

Heidi Hartikainen, Afsaneh Razi, and Pamela Wisniewski. 2021. 'If You Care About Me, You'll Send Me a Pic' - Examining the Role of Peer Pressure in Adolescent Sexting. In Companion Publication of the 2021 Conference on Computer Supported Cooperative Work and Social Computing (CSCW' 21 Companion), October 23-27, 2021, Virtual Event, USA. ACM, New York, NY, USA, 5 pages. https://doi.org/10.1145/xxxxxxx.xxxxxxx
\end{abstract}

\section{INTRODUCTION}

Children grow up in an increasingly digital world and their learning, creating, communicating, and socializing processes are affected by technology from very early on [28]. More than half of teens $(57 \%)$ aged 13-17 report having started friendships online and 55\% say they have used social media to flirt [22]. Internet affords adolescents opportunities to form relationships and explore sexual identities [36], but using it to seek intimacy has also become a key stressor [38], and can pose risks to their safety and wellbeing. Adolescents are using the Internet to seek support and advice about relationships [20] and sexual health $[19,33]$. When it comes to online sexual risk, parents and researchers often focus on sexual risk from strangers. However, adolescents are more often victimized by people they know $[12,32]$. They also struggle more to reject solicitations such as requests for nudes or sexts from people they know, than from strangers [29]. More research is warranted concerning the issues adolescents seek support for, and on the social support they receive online about their online sexual experiences $[2,17]$. We build upon prior research by analyzing social media trace data from an online peer support platform to answer the following research questions:

Permission to make digital or hard copies of all or part of this work for personal or classroom use is granted without fee provided that copies are not made or distributed for profit or commercial advantage and that copies bear this notice and the full citation on the first page. Copyrights for components of this work owned by others than the author(s) must be honored. Abstracting with credit is permitted. To copy otherwise, or republish, to post on servers or to redistribute to lists, requires prior specific permission and/or a fee. Request permissions from permissions@acm.org.

CSCW'21 Companion, October 23-27, 2021, Virtual Event, USA

( $) 2021$ Copyright held by the owner/author(s). Publication rights licensed to ACM ACM ISBN xxx-x-xxxx-xxxx-x

https://doi.org/10.1145/xxxxxxx.xxxxxxxx
- RQ1) How does peer pressure play a role in adolescent sexting?

- RQ2) What is the advice teens received for combatting peer pressure for sexting?

\section{RELATED WORK}

Risky Adolescent Online Sexual Experiences and Peer Pressure. Risky online sexual experiences include interactions such as unwanted solicitations [25], looking for sexual partners [26], grooming [15], abuse, and sexting [24, 36]. Researchers suggest teens struggle more to reject solicitations such as requests for nudes or sexts from people they know than from strangers [29]. However, much of the research on online sexual risk concentrates on risks posed by strangers. Previous research also indicates acceptance of sexting by friends and romantic partners [37] or popular peers [23] is associated with increased sexting. Concerning peer pressure, researchers have suggested more research should pay attention to who is the intended recipient of the sexts to take into account the context in which sexting takes place [37], as well as the role trust plays in the sexting decisions [10]. We add to this discussion by investigating what online sexual experiences adolescents seek support for related to people they already know, and the role pressure plays. Furthermore, previous research on risky adolescent online experiences often relies on adolescents' self-report data [27]. Literature on sexting peer influence suggest using other types of data as adolescents might feel monitored and give socially desirable answers on sensitive issues [10]. In our work, we utilize digital trace data from an online peer support platform as it is more reflective of teens' online behaviors and experiences than self-report data $[1,16,30,31]$. It allows us to get a researcher independent glimpse into risky adolescents' online sexual experiences and peer support for sexual risk.

Online Peer Support for Sexual Risk. Peers can be very influential on teens' behavior [8], and their support is important when coping with stressful situations $[6,11]$. Peer support is important also when discussing online sexual experiences [3, 4, 20]. Much of the current research on peer support focuses on adults, and we add to this discussion by examining what kind of support adolescents receive to deal with these situations. Online social support for sensitive topics such as sexuality is important for adolescents [14, 34, 39] as they might not feel comfortable receiving professional help or talking to adults about these topics $[18,40]$. They might also feel limited when talking to peers due to norms and expectations they can circumvent online [13]. The majority of teens who face difficulties in their relationships do not seek offline help because they might fear judgment, have concerns about confidentiality, or lack knowledge about available support [21]. They turn to online support when they feel more comfortable interacting with people they do not know offline [13]. Previous research has utilized digital trace 
data for researching teens' online responses to sex and relationships. Kim et al. [21] analyzed anonymous responses to posts about relationship difficulties and found teens often advise peers to terminate relationships than seeking help or communicate [21]. Suzuki and Calzo [34] investigated a moderated health support website to understand questions related to health, sexuality, and relationship that teens asked about and the types of support they receive. They found teens were provided advice through opinions (63\%), actionable advice (44\%), information (37\%), personal experiences (33\%), and emotional support (12\%). This work provides insights about adolescent support-seeking behavior, as well as their responses concerning their sexual health and romantic relationships. However, it has not specifically investigated teens' online sexual experiences with people they know or the role of peer pressure in adolescent sexting, which our research investigates further.

\section{METHODS}

Dataset and scoping. We licensed a dataset from a mental health peer support platform catering mainly to teens and young adults. We anonymized the name of this platform to protect the individuals on our dataset. On this platform, users can post content and comment on others' posts. Interactions are semi-anonymous: users share a photo and screen name with others. They have the option to post with their username visible or anonymously. The platform is moderated, but the ratio of moderators to posters is low (0.00007). The original dataset included over 5 million posts and 15 million comments from 2011- 2017. It was scaled to a feasible size for qualitative analysis by running a query to identify posts by a) adolescents aged 13-17 that were seeking support for b) online sexual experiences (not offline) with people they know (not strangers). We used popular social media, and sexual jargon by teens [35] and added terms while reading through posts in an iterative process The posts were divided among researchers that coded for relevancy. It was relevant if: 1) it involved online sexual experience, 2) with a person the poster indicated knowing, and 3) it sought support for the online sexual experience. The reason for the criteria was that adolescents have more difficulty rejecting sexual solicitations from persons they know [29]. We defined support seeking to direct support seeking (asking for help) and indirect support seeking (hinting problems exist) [5]. This scoping resulted in a dataset of 837 support-seeking posts made by 721 unique users. The average age of posters was 15.5 . $78 \%$ were female, $12 \%$ were male, $10 \%$ did not disclose gender. 3050 associated peer comments were made by 1,657 unique commenters whose average age is approximately 19 years old $(\mathrm{YO})(\mathrm{STD}=6.5)$, the gender distribution is $58 \%$ females, $35 \%$ male, and $7 \%$ identified their gender as non-binary or preferred not to disclose.

Qualitative thematic analysis. We started our analysis by doing a qualitative thematic analysis [7] of posts in our dataset to identify the online sexual experiences with people they know that adolescents seek support for. To develop the codebook three coders discussed posts to come up with initial codes and descriptions for scenarios that teens are seeking help in. They were discussed between five researchers; similar codes were merged as consensus was reached. Inter-rater reliability for coding was $84.4 \%$. After the initial coding of posts was completed, a summary of post results was prepared and the first author went through them to identify how peer pressure plays a role in adolescent sexting (RQ1). Next, a qualitative thematic analysis of associated peer comments was carried to find out what kind of support adolescents receive concerning online sexual experiences The codebook was based on an existing classification of social support $[6,11]$, Inter-rater reliability for coding was $95.4 \%$. After the initial coding of comments was completed, a summary of peer support comment results was prepared and the first author went through them to identify advice teens receive for combatting peer pressure for sexting (RQ2). The results were discussed between authors, and a narrative synthesis was prepared.

Ethical considerations. Our research protocol was evaluated by the university's Institutional Review Board which determined it exempt from human subjects' review as personally identifiable information of users was removed before the dataset was shared with us. When reporting findings, we anonymized and paraphrased quotes to ensure they cannot be traced back online. Data was disguised by removing verbatim quotes and pseudonyms and inserting false details that don't matter in the context [9]. To further protect the identity of the adolescents in our data analysis, we anonymized the name of the platform. Because the dataset included sensitive issues such as sex and self-harm, research team completed training for working with human subjects before accessing it. Furthermore, as content was potentially disturbing, the team were encouraged to take breaks if needed and to discuss any concerns.

\section{RESULTS}

We will first present results concerning how peer pressure plays a role in adolescent sexting (RQ1). This is followed by results concerning the advice adolescents get concerning combatting this peer pressure (RQ2).

\subsection{RQ1: How does peer pressure play a role in adolescent sexting?}

From the support seeking posts, it was visible that teens view sexting as a normal part of sexuality, and they used the platform to share details about their positive experiences: "my online crush and I used snap for it's original purpose and I'm just happy. nothing can go wrong" (Female, $14 \mathrm{YO}$ ). Positive experiences expressed were often about developments in relationships with a friend, crush, or significant other. Sexting was viewed as an extension to both online and "real-life" relationships. Because it was the expectation that a girlfriend or a boyfriend will be interested in engaging, teens felt hurt or rejected if for some reason their significant other was not keen: 'I'm confused. I've been with my boyfriend for 5 months and we haven't done anything but kiss. I said I'd send nudes and he got mad and said how I shouldn't send nudes to people." (Female, 14 YO). Teens also expressed conflicting feelings about sexting, for example wondering if engaging somehow makes them a bad person<strike $>:</$ strike $>$ "But does it make me a slut i sent a guy I know and like a pic of my boobies? what will people think?" (Female, 16 YO). Like in the example, often the excitement of exploring their sexuality also presented with conflicting feelings of self-doubt and a fear of getting caught. 
Because sexting was viewed as an extension in an adolescent relationship, pressure to engage is sometimes presented in subtle ways. For example, teens brought up situations where their significant other seemed disappointed they did not engage and were asking peers if sexting is something that they should do to keep their significant other happy: "Am I in the wrong for not sending $a$ boyfriend a pic when he is horny?" (Female, $17 \mathrm{YO}$ ) - Even if they are not necessarily ready to do it themselves: "The boyf asked me to send a sexy pic and $i$ don't want to. $i$ don't want to make him upset if $i$ say no. he says he cares and that $i$ shouldn't doubt myself but $i$ just really don't want to yet. what should I do?" (Female, 15 YO). In some cases, the pressure from a dating partner continued even after the teen had said they do not want to: "My boyfriend keeps pressuring me to send nudes and I don't want to. Should I break up? I've said I don't want to but he won't respect it" (Female, 14 YO). In their posts, teens were asking their peers for help on how they should handle these kinds of difficult situations - asking for help to identify normal online sexual behavior in a dating relationship, and how to draw boundaries in one partner is ready to sext, and one is not.

Pressure to engage in sexting also presented in situations where teens were hoping to start up a new relationship with someone. Some expressed being concerned that perhaps their crush is only pretending to be interested in them to get them to send them nudes: "I feel he only asked me out cause I'm vulnerable and have a low self-esteem, he thinks he's going to get me to show him stuff I DON'T want to. he keeps saying if you care about me, you'll send me a pic“" (Female, $17 \mathrm{YO}$ ). This was also visible in relationships teens were looking to form with persons they had met online: "LDR for me is crying bc all they want is nudes. I never send them because I'm fat and ugly." (Female, 16 YO). Adolescents interested in a dating relationship online and offline brought up fears of being manipulated into sexting too soon in relationships where trust had not yet been established. Like in the examples above, often fears of being manipulated were tied with self-esteem issues.

Teens who felt pressure to engage in sexting brought up fears that their dating partner or crush might reject them if they do not engage. They were trying to balance between keeping their partner happy and not doing anything that they are not ready to do. Rejection indeed emerged as a consequence in some posts. Some indicated being their partner broke up with them after they chose not to give in to being pressured: "We weren't even dating long and he already broke up with me because $i$ wont sext or send nudes as a way of building trust with him" (Female, $16 \mathrm{YO}$ ). Some that gave in to the pressure were rejected after sexting: "I have this older guy. I am very much in love, he used to love me. I sent the nudes and he barely talks to me now." (Female, 16 YO). Teens who got rejected or ghosted were often using the platform to try and find help in dealing with their emotions, seeking validation and experiences from others who had experienced the same.

Overall, pressure to engage in sexting was seen to play a role in both online and offline relationships of adolescents of those adolescents whose posts were included in our dataset. Teens were struggling to draw boundaries, trying to figure out what is normal sexual behavior in a relationship. In established relationships, the pressure from another person could be subtle, and teens were wondering if they should do it to keep the other person happy. Related to trust, especially in new relationships teens were wondering at what time it is OK to engage - And voiced out their fears that perhaps the other person is just using them to get sexual content. Teens were also worrying about what will happen if people find out, or the material will be leaked. Sending sexts was seen as an expression of love - and interestingly it was even seen as a sign of not trusting your partner if you refused to send them nudes. In their posts, teens were sharing experiences and asking peers for actionable advice on how to navigate difficult situations such as how to tell your significant other you do not want to engage without hurting their feelings, or how to respond to someone who has been pressuring them to engage.

\subsection{RQ2: What advice do teens receive for combatting peer pressure for sexting?}

In their responses peers stressed the importance of trust in relationships and reminded the teens that in a healthy relationship their partner should not pressure them to do anything they are not comfortable with: "Never let a guy guilt you into doing something you're not comfortable with!" (Female, $17 \mathrm{YO})$ ), "a good girlfriend will not pressure you" (Male, $23 \mathrm{YO}$ ). Teens were encouraged to tell their partner if their requests are unwanted or if they come early in a relationship: "Fust tell him you're not comfortable sending nudes as you haven't dated long. He should understand" (Female, 18). Peers reminded teens that in the end whether to sext is their own decision, but they should only engage if they are sure that they are comfortable in doing so. Teens who feared rejection if they do not engage were reminded that they should not feel bad for saying no: "don't feel guilty, you have nothing to be guilty about" (Female, 17 $\mathrm{YO})$.

Teens were advised that if the other person continues to pressure them, they should break up or block the other person on social media: "if he continues to make you uncomfortable tell him you don't feel that way. if it gets worse just block him." (Female, 16 YO ). Peers reminded the teens that while it is important to stand their ground if they want to say no but it is ultimately their own decision: "Don't send pics if you don't feel like it. If she threatened to leave over that she's not worth it. but if you do send them leave your face out" (Female, $15 \mathrm{YO}$ ). Peers tried to signal the teens to understand that putting pressure on your significant other, but ultimately understood that relationships are important to them - And in just in case, shared this kind of actionable advice to help them to engage safely should they choose to do so.

Peers often combined their advice with personal stories and experiences like in the following examples: "don't do it. If he loved you he wouldn't put you in that position. I've been there and I did it to make him happy. Only to find out was cheating." (Female, 19 YO). "I was in this situation once, it didn't end well [...] end it before it gets worse, I thought I loved him too, but it was what it was, him taking advantage of my vulnerability." (Male, $21 \mathrm{YO}$ ). In addition to empathizing, the goal of sharing personal experiences with advice seemed to be to show the teen the person knows what they are talking about and therefore can make valid points worth considering.

Overall, advice was often combined with personal stories to empathize. Peers told the teens that in a healthy partnership there should not be any pressure to engage. They advised the teens to 
discuss their feelings honestly with their partners, and not to succumb to pressure. Teens were encouraged to wait until they are ready to build healthy trusting relationships and to end relationships with those not respecting their boundaries. However, peers also understood the urge to engage with someone you love to keep them happy, and gave actionable advice just in case, so that the teens could engage safely should they choose to do so.

\section{DISCUSSION AND CONCLUSIONS}

We contributed to the existing body of knowledge by identifying youth-focused beliefs about sexting through analyzing 1) How peer pressure plays a role in adolescent sexting, and b) what advice teens receive for combatting peer pressure for sexting.

Role of pressure in adolescent sexting. Like in previous research $[23,37]$ pressure from friends, romantic partners, and popular teens was seen to affect adolescent sexting decisions. In our data, the influence from romantic partners, both in offline and online environments was most evident. The pressure to engage could be quite subtle. Relationships were important to the teens, who were wondering for example if they should go ahead even if they were not necessarily feeling ready, to keep their partner happy. Especially in new relationships, teens expressed sometimes being worried if their partner might be leading them on, expressing caring about them, when they are just using them for nudes. The influence of friends and peers was visible in the background, as teens seemed to view sexting in their posts as a normal part of adolescent relationships, something that is accepted. However, teens also had conflicting feelings about it, wondering what will happen if someone finds out, if their friends or family will judge their behavior, or think they are promiscuous. Romantic relationships were important to the teens, who expressed fearing rejection both if they choose to not engage, and if they do, for example, if the other person does not like their photos. In their posts, teens were struggling to draw boundaries regarding normal sexting behavior in new and established relationships and asking peers for actionable advice on how to navigate any difficult situations they had with their partner. This also links to the discussion regarding the role of trust in sexting decisions [10]; Teens being worried about what others might think if they find out they have been sexting, are expressing concern that the sexts might not stay confidential. Teens were also trying to figure out at what phase in a relationship it is the right time to sext, how to make sure the other person is trustworthy and not just using you. Interestingly, in our data, refusing to sext with your partner was even seen as expressing a lack of trust in them ('If you trusted me, you would send me nudes').

Advice to combat peer pressure. When giving advice to teens feeling pressured to engage peers stressed the importance of selfrespect and healthy relationships and advised the teens to wait until they feel ready and to discuss with their partner any concerns they have - advising that a good partner should respect the boundaries they set. Peers also often advised teens to end relationships where the pressure to sext was continuous, which is in line with previous research [21]. Actionable advice was often combined with personal experiences and peers condemned any pressure and manipulation to sext. They however also showed empathetic understanding to the urge to engage with someone close to you and provided teens advice on how they should go about sexting in a safe way should they choose to engage in sexting - for example by making sure they are not identifiable in the materials.

Further research. Understanding what kind of issues teens seek support for their online sexual experiences, and what kind of peer support they receive is important when designing online systems that facilitate social support for adolescents. We believe more research would be warranted concerning how teens leverage the internet to negotiate with their peers what is acceptable online sexual behavior. Concerning pressure and sexting, especially interesting would be to research further the conflicting emotions related to sexting expressed in teen posts: Sexting was seen as a natural part of adolescent relationships (everyone is doing it so it's $\mathrm{OK})$, but there was still a hint of doubt and shame involved in many sexting decisions (but will everyone think worse of me if I sext?). An interesting finding to probe further would also be sexting as an expression of trust in adolescent relationships. Working with digital trace data provided us a researcher independent glimpse into the topic, and we see it especially valuable when working with topics like these, where adolescents might not be comfortable talking about face-to-face. However, to get a more comprehensive picture of the role of pressure in adolescent sexting, it would be valuable to combine it with data collected with other methods. In the future, we plan to continue our research by carrying out interviews with teens to further explore the themes of pressure, peer influence, and trust in adolescent sexting uncovered in this paper. Since we used online posts and comments on a mental health support platform, our results might be geared more toward adolescents with mental health concerns. Therefore, future research should consider datasets from other platforms to investigate the generalization of our results.

\section{ACKNOWLEDGMENTS}

We thank Pia Nelson, Gabriel Laaroussi, and Gabriel Mariz, who assisted with the qualitative data coding. This research is partially supported by the U.S. National Science Foundation under grants IIP1827700 and IIS-1844881 and by the William T. Grant Foundation grant \#187941. Any opinions, findings, and conclusions or recommendations expressed in this material are those of the authors and do not necessarily reflect the views of the research sponsors

\section{REFERENCES}

[1] Agha, Z., Chatlani, N., Razi, A., and Pamela Wisniewski Towards Conducting Responsible Research with Teens and Parents regarding Online Risks. CHI 2020 Extended Abstracts.

[2] Ali, K., Farrer, L., Gulliver, A. and Griffiths, K.M. 2015. Online Peer-to-Peer Support for Young People With Mental Health Problems: A Systematic Review. FMIR Mental Health. 2, 2 (2015), e19. DOI:https://doi.org/10.2196/mental.4418.

[3] Andalibi, N., Haimson, O.L., Choudhury, M.D. and Forte, A. 2018. Social Support, Reciprocity, and Anonymity in Responses to Sexual Abuse Disclosures on Social Media. ACM Transactions on Computer-Human Interaction. 25, 5 (Oct. 2018), 1-35. DOI:https://doi.org/10.1145/3234942.

[4] Andalibi, N., Haimson, O.L., De Choudhury, M. and Forte, A. 2016. Understanding Social Media Disclosures of Sexual Abuse Through the Lenses of Support Seeking and Anonymity. Proceedings of the 2016 CHI Conference on Human Factors in Computing Systems - CHI '16 (Santa Clara, California, USA, 2016), 3906-3918.

[5] Barbee, A.P. and Cunningham, M.R. 1995. An experimental approach to social support communications: Interactive coping in close relationships. Annals of the International Communication Association. 18, 1 (1995), 381-413.

[6] Braithwaite, D.O., Waldron, V.R. and Finn, J. 1999. Communication of Social Support in Computer-Mediated Groups for People With Disabilities. Health Communication. 11, 2 (Apr. 1999), 123-151. DOI:https://doi.org/10.1207/s15327027hc1102_ 2 . 
[7] Braun, V. and Clarke, V. 2012. Thematic analysis. APA handbook of research methods in psychology, Vol 2: Research designs: Quantitative, qualitative, neuropsychological, and biological. American Psychological Association. 57-71.

[8] Brechwald, W.A. and Prinstein, M.J. 2011. Beyond Homophily: A Decade of Advances in Understanding Peer Influence Processes. Fournal of Research on Adolescence: The Official fournal of the Society for Research on Adolescence. 21, 1 (Mar. 2011), 166-179. DOI:https://doi.org/10.1111/j.1532-7795.2010.00721.x.

[9] Bruckman, A. 2002. Studying the amateur artist: A perspective on disguising data collected in human subjects research on the Internet. Ethics and Information Technology. 4, 3 (Sep. 2002), 217-231. DOI:https://doi.org/10.1023/A:1021316409277.

[10] Burén, J., Holmqvist Gattario, K. and Lunde, C. 2021. What Do Peers Think About Sexting? Adolescents' Views of the Norms Guiding Sexting Behavior. fournal of Adolescent Research. (May 2021), 07435584211014837. DOI:https://doi.org/10 $1177 / 07435584211014837$.

[11] Cutrona, C.E. and Suhr, J.A. 1992. Controllability of Stressful Events and Satisfaction With Spouse Support Behaviors. Communication Research. 19, 2 (Apr. 1992), 154-174. DOI:https://doi.org/10.1177/009365092019002002.

[12] Doornwaard, S.M., Bickham, D.S., Rich, M., ter Bogt, T.F.M. and van den Eijnden, R.J.J.M. 2015. Adolescents' use of sexually explicit internet material and their sexual attitudes and behavior: Parallel development and directional effects. Developmental Psychology. 51, 10 (Oct. 2015), 1476-1488. DOI:https //doi.org/10.1037/dev0000040.

[13] Ellison, N.B., Blackwell, L., Lampe, C. and Trieu, P. 2016. "The Question Exists, but You Don't Exist With It": Strategic Anonymity in the Social Lives of Adolescents. Social Media + Society. 2, 4 (Oct. 2016), 2056305116670673. DOI:https://doi.org/10 $1177 / 2056305116670673$

[14] Forte, A., Dickard, M., Magee, R. and Agosto, D.E. 2014. What do teens ask their online social networks?: social search practices among high school students. Proceedings of the 17th ACM conference on Computer supported cooperative work \& social computing - CSCW' 14 (Baltimore, Maryland, USA, 2014), 28-37.

[15] Gámez-Guadix, M., Almendros, C., Calvete, E. and De Santisteban, P. 2018. Persuasion strategies and sexual solicitations and interactions in online sexual grooming of adolescents: Modeling direct and indirect pathways. Fournal of Adolescence 63, (Feb. 2018), 11-18. DOI:https://doi.org/10.1016/j.adolescence.2017.12.002.

[16] Hartikainen, H., Iivari, N. and Kinnula, M. 2016. Should We Design for Control, Trust or Involvement? A Discourses Survey about Children's Online Safety. Proceedings of the The 15th International Conference on Interaction Design and Children (Manchester, United Kingdom, Jun. 2016), 367-378

[17] Hartikainen, H., Razi, A. and Wisniewski, P. 2021. Safe Sexting: The Advice and Support Adolescents Receive from Peers regarding Online Sexual Risks. Proceedings of the ACM on Human-Computer Interaction. 5, CSCW1 (Apr. 2021) 42:1-42:31. DOI:https://doi.org/10.1145/3449116.

[18] Hershkowitz, I., Lanes, O. and Lamb, M.E. 2007. Exploring the disclosure of child sexual abuse with alleged victims and their parents. Child Abuse \& Neglect. 31, 2 (Feb. 2007), 111-123. DOI:https://doi.org/10.1016/j.chiabu.2006.09.004.

[19] Kang, M. and Quine, S. 2007. Young people's concerns about sex: unsolicited questions to a teenage radio talkback programme over three years. Sex Education 7, 4 (Nov. 2007), 407-420. DOI:https://doi.org/10.1080/14681810701636010.

[20] Kim, J.-E., Weinstein, E.C. and Selman, R.L. 2017. Romantic Relationship Advice From Anonymous Online Helpers: The Peer Support Adolescents Exchange. Youth \& Society. 49, 3 (Apr. 2017), 369-392. DOI:https://doi.org/10.1177/ $0044118 X 15604849$

[21] Kim, J.-E., Weinstein, E.C. and Selman, R.L. 2015. Romantic Relationship Advice From Anonymous Online Helpers: The Peer Support Adolescents Exchange Youth \& Society. (Sep. 2015). DOI:https://doi.org/10.1177/0044118X15604849.

[22] Lenhart, A., Anderson, M. and Smith, A. 2015. Teens, Technology and Romantic Relationships. Pew Research Center.
[23] Maheux, A.J., Evans, R., Widman, L., Nesi, J., Prinstein, M.J. and Choukas-Bradley, S. 2020. Popular Peer Norms and Adolescent Sexting Behavior. Fournal of adolescence. 78, (Jan. 2020), 62-66. DOI:https://doi.org/10.1016/j.adolescence.2019.12. 002 .

[24] Martellozzo, E. 2019. Chapter 4 - Online Child Sexual Abuse. Child Abuse and Neglect. I. Bryce, Y. Robinson, and W. Petherick, eds. Academic Press. 63-77.

[25] Mitchell, K.J., Jones, L.M., Finkelhor, D. and Wolak, J. 2014. Trends in Unwanted Online Experiences and Sexting. Crimes against Children Research Center.

[26] Pascoe, C.J. 2011. Resource and Risk: Youth Sexuality and New Media Use. Sexuality Research and Social Policy. 8, 1 (Mar. 2011), 5-17. DOI:https://doi.org/10. 1007/s13178-011-0042-5.

[27] Pinter, A.T., Wisniewski, P.J., Xu, H., Rosson, M.B. and Caroll, J.M. 2017. Adolescent Online Safety: Moving Beyond Formative Evaluations to Designing Solutions for the Future. Proceedings of the 2017 Conference on Interaction Design and Children - IDC '17 (Stanford, California, USA, 2017), 352-357.

[28] Prensky, M. 2001. Digital Natives, Digital Immigrants Part 2: Do They Really Think Differently? On the Horizon. 9, 6 (Nov. 2001), 1-6. DOI:https://doi.org/10. 1108/10748120110424843.

[29] Razi, A., Badillo-Urquiola, K. and Wisniewski, P. 2020. Let's Talk about Sext: How Adolescents Seek Support and Advice about Their Online Sexual Experiences. (Honolulu, HI, USA, Apr. 2020).

[30] Razi, A., Kim, S., Choudhury, M.D. and Wisniewski, P. 2019. Ethical Considerations for Adolescent Online Risk Detection AI Systems. Technical Report \#ID 3503956. Social Science Research Network.

[31] Razi, A. and Wisniewski, P. 2019. Qualitative Analysis on Large Scale Social Media Data for Adolescent Online Safety. Technical Report \#ID 3503959. Social Science Research Network.

[32] Sklenarova, H., Schulz, A., Schuhmann, P., Osterheider, M. and Neutze, J. 2018. Online sexual solicitation by adults and peers - Results from a population based German sample. Child Abuse \& Neglect. 76, (Feb. 2018), 225-236. DOI:https: //doi.org/10.1016/j.chiabu.2017.11.005.

[33] Suzuki, L.K. and Calzo, J.P. 2004. The search for peer advice in cyberspace: An examination of online teen bulletin boards about health and sexuality. Fournal of Applied Developmental Psychology. 25, 6 (Nov. 2004), 685-698. DOI:https://doi. org/10.1016/j.appdev.2004.09.002.

[34] Suzuki, L.K. and Calzo, J.P. 2004. The search for peer advice in cyberspace: An examination of online teen bulletin boards about health and sexuality. Fournal of Applied Developmental Psychology. 25, 6 (Nov. 2004), 685-698. DOI:https://doi. org/10.1016/j.appdev.2004.09.002.

[35] Team, T.B. Teen Text Speak Codes Every Parent Should Know. Bark.

[36] Tolman, D.L. and McClelland, S.I. 2011. Normative Sexuality Development in Adolescence: A Decade in Review, 2000-2009: ADOLESCENT SEXUALITY. Fournal of Research on Adolescence. 21, 1 (Mar. 2011), 242-255. DOI:https://doi.org/10. 1111/j.1532-7795.2010.00726.x.

[37] Van Ouytsel, J., Ponnet, K., Walrave, M. and d'Haenens, L. 2017. Adolescent sexting from a social learning perspective. Telematics and Informatics. 34, 1 (Feb. 2017), 287-298. DOI:https://doi.org/10.1016/j.tele.2016.05.009.

[38] Weinstein, E.C. and Selman, R.L. 2016. Digital stress: Adolescents' persona accounts. New Media \& Society. 18, 3 (Mar. 2016), 391-409. DOI:https://doi.org/ $10.1177 / 1461444814543989$.

[39] White, M. and Dorman, S.M. 2001. Receiving social support online: implications for health education. Health Education Research. 16, 6 (Dec. 2001), 693-707. DOI:https://doi.org/10.1093/her/16.6.693.

[40] Yeo, T.E.D. and Chu, T.H. 2017. Sharing "Sex Secrets" on Facebook: A Conten Analysis of Youth Peer Communication and Advice Exchange on Social Media about Sexual Health and Intimate Relations. Fournal of Health Communication. 22, 9 (Sep. 2017), 753-762. DOI:https://doi.org/10.1080/10810730.2017.1347217. 